\title{
Effect of freeze-drying and extraction solvents on the total phenolic contents, total flavonoids and antioxidant activity of different Rabbiteye blueberry genotypes grown in New Zealand
}

\author{
Janyawat Vuthijumnok ${ }^{1}$, Abdul-Lateef Molan ${ }^{1,2^{*}}$ and Julian A. Heyes ${ }^{1}$ \\ ${ }^{1}$ Institute of Food, Nutrition and Human Health, Massey University, Palmerston North, New Zealand \\ ${ }^{2}$ Present address: Department of Biology, College of Sciences, Diyala University, Diyala, Iraq
}

\begin{abstract}
The effects of freeze-drying and extraction solvents on total phenolic content (TPC), total flavonoid content (TFC) and antioxidant properties of five rabbiteye blueberry genotypes, namely 'Centurion', 'Maru', 'Rahi', 'Ono', and 'Tifblue', were investigated. Significant $(P<0.05)$ differences in TPC, TFC and antioxidant activities were found between extracts from different genotypes and between freeze-dried and unfreeze-dried samples. Crude water extracts from the berries of 'Tifblue' had the highest TPC and TFC followed by 'Ono', 'Centurion', 'Rahi', and 'Maru'. Acidification by 5\% (v/v) formic acid resulted in a significant increase $(P<$ $0.05)$ in TPC and TFC in water extracts and antioxidant activity as measured by ferric-reducing antioxidant power assay (FRAP) and oxygen radical absorbance capacity (ORAC) when compared with unacidified water. The results showed that freeze dried whole berries extracted in 5\% aqueous formic acid demonstrated significantly higher $(P<0.0001)$ antioxidant activity, as measured by FRAP and ORAC, than those extracted in water alone and this was the case for all the tested genotypes. Overall, a strong positive correlation was observed between TPC and TFC and antioxidant activity measured by FRAP or ORAC, indicating that these compounds are significant contributors to the antioxidant activity of the tested blueberry genotypes.
\end{abstract}

Keywords: antioxidant activity, blueberry genotypes, FRAP, freeze drying, ORAC, phenolic compounds

\section{Introduction}

Fruits and vegetables are widely recognised for their health benefits. High consumption of fruits is related to lower rates of cardiovascular diseases, cancers and others chronic diseases [1]. This effect has been ascribed to antioxidant activities found in fruits and vegetables although more recent research suggests these compounds are directly affecting gene expression in humans rather than simply acting as antioxidants [2]. Apart from vitamin $\mathrm{C}$, vitamin $\mathrm{E}$ and carotenoids, phytochemical compounds such as phenolic compounds contribute to antioxidant properties of fruits and vegetables [3].

Several studies showed that blueberries are among the fruits that have the highest in vitro antioxidant activity [4]. It is also widely known that blueberry fruits contain high amounts of phenolic compounds especially anthocyanins [5]. In humans, polyphenols demonstrate health benefit via two major functions which are inhibition of enzyme activities such as xanthine oxidase and antioxidant activity [6]. The important phenolic compounds found in blueberries are phenolic acids (eg. chlorogenic acid), flavonoids (eg. anthocyanins) and tannins [3]. The concentration of plant phenolic compounds is correlated with their antioxidant activity [7, 8].

Flavonoids are secondary metabolites in plants which are always found in bound forms. They are mainly glycosylated with sugar molecules such as rhamnose and glucose. In addition to the high antioxidant activity, several researches showed that flavonoid could possibly prevent several types of cancers such as colon, breast, skin, oral and prostate [9]. The major flavonoid in blueberries is anthocyanin which shows various biological activities [10].

Extraction solvents are one of the most important factors in studying phytochemical compounds such as phenolic compounds from plant or medicinal foods. Phenolic compounds are polar compounds so they are better extracted by polar solvents such as ethyl acetate, acetone or methanol [11]. Tuberoso et al. [12] reported that ethanol was the most effective solvent for phenolic compounds extraction from myrtle berries whilst distilled water showed low extracting ability. However, harsh solvents are not suitable for preparing extracts for human consumption since the solvent residue may contaminate the final products. Kalt et al. [13] found that acid added to the solvents not only helped in extraction but also stabilized anthocyanin in the extracts. In New Zealand, fresh blueberries are available only from November till late April. Freezing is the easiest way to keep them available all year round. At $-20^{\circ} \mathrm{C}$, the anthocyanin content in blueberry was stable for 3 months as reported by Lohachoompol et al. [5]. However, the best way to store blueberries for long periods is drying. Oven drying is economical but antioxidant capacity of plant materials might be lost. Therefore, freeze drying is of interest since antioxidant capacity of plant extract remains unchanged [14]. 
In this study, the effects of solvents and freeze drying on antioxidant activities as measured by FRAP and ORAC, total phenolic contents and total flavonoid contents in five rabbiteye blueberry genotypes were studied. In addition, the correlation between the antioxidant activities and polyphenolic contents was evaluated.

\section{Materials And Methods}

Five genotypes ('Centurion', 'Maru', 'Rahi', 'Ono' and 'Tifblue') of fresh rabbiteye (Vaccinium ashei) blueberries were purchased from a blueberry farm in Waikato, New Zealand, at commercial maturity. Berries were commercially graded and frozen the same day. Some were subsequently freeze-dried under vacuum at $50^{\circ} \mathrm{C}$ and stored at $-20^{\circ} \mathrm{C}$. The remainder were stored frozen at $-20^{\circ} \mathrm{C}$ until analysis.

\subsection{Crude extracts}

Hundred gram batches of frozen berries were extracted either in $100 \mathrm{~mL}$ distilled water only or in $5 \%$ aqueous formic acid $(100 \mathrm{~mL}$ ) in food processor (Breville, WT 400 MINI WIZZ processor). The mixture was centrifuged at 22,000 $\mathrm{g}$ for 10 minutes. The pomace by-product from juice extraction was discarded while the supernatant was collected and used for determination of the total phenolic content (TPC), total flavonoid content (TFC), and antioxidant activity. Separately, freeze-dried berries were ground into powder using coffee grinder (Breville, CG2B) and $100 \mathrm{mg}$ aliquots were extracted in $10 \mathrm{~mL}$ water and used for determination of TPC, TFC and antioxidant activities.

\subsection{Determination of total phenolic concentration (TPC)}

Total phenolic concentration (TPC) was measured using Folin-Ciocalteu reagent as described previously (Molan et al., 2009). Briefly, an aliquot of $12.5 \mu \mathrm{L}$ was mixed with $250 \mu \mathrm{L}$ of $2 \% \mathrm{Na}_{2} \mathrm{CO}_{3}$ in $96-$ well microplates, the mixture was left for 5 minutes at room temperature and then an aliquot of $12.5 \mu \mathrm{L}$ of $50 \%$ Folin-Ciocalteu reagent was added to the mixture. The mixture was allowed to react at ambient temperature for 30 minutes. Then the absorbance was measured at $650 \mathrm{~nm}$ using microplate reader (ELX 808 Ultra microplate reader, BIO-TEK instrument) with $\mathrm{KC} 4$ software. TPC of the blueberry samples were expressed as mg gallic acid equivalent (GAE)/g frozen weight.

\subsection{Determination of total flavonoid concentration (TFC)}

Total flavonoid concentration (TFC) was determined using aluminum chloride colorimetric assay as described by Kumar et al. [15] with some modifications. In 96-well plates, $25 \mathrm{uL}$ of blueberry samples were mixed with $100 \mu \mathrm{L}$ distilled water and $5 \% \mathrm{NaNO}_{2}(7 \mu \mathrm{L})$. The plate was left at room temperature for 5 minutes. Then $10 \% \mathrm{AlCl}_{3}(7 \mu \mathrm{L})$ was added to the mixture and incubated for 5 minutes and then $1 \mathrm{~mol} / \mathrm{L} \mathrm{NaOH}(50 \mu \mathrm{L})$ and distilled water $(60 \mu \mathrm{L})$ were added to the mixture. The absorbance of the mixture was measured at $490 \mathrm{~nm}$. The TFC in blueberry samples were expressed as $\mathrm{mg}$ catechin equivalent (CE) per gram frozen berries.

\subsection{Ferric Reducing Antioxidant Power (FRAP)}

FRAP is a widely used method for determination of antioxidant activity of tested samples [16]. The philosophy of this assay is based on the ability of the antioxidant compounds to reduce the ferrictripyridyltriazine (TPTZ) complex to its ferrous form. In this study, the procedure described by Benzie and Strain [16] with some modifications [17] was followed. Briefly, the FRAP reagent was prepared by mixing 300 $\mathrm{mmol} / \mathrm{L}$ sodium acetate buffer $\mathrm{pH} 3.6,10 \mathrm{mmol} / \mathrm{L} \mathrm{TPTZ} \mathrm{in} 40 \mathrm{mmol} / \mathrm{L} \mathrm{HCl}$ and $20 \mathrm{mmol} / \mathrm{L}$ ferric chloride $(10: 1: 1)$. Aliquots of $8.5 \mu \mathrm{L}$ of blueberry samples were mixed with FRAP reagent $(275 \mu \mathrm{L})$ in 96 -well plates. Each plate was incubated at $37^{\circ} \mathrm{C}$ in the dark for 30 minutes and then the absorbance of the mixture was measured at $595 \mathrm{~nm}$. The FRAP values were expressed as $\mu$ mol Trolox equivalent (TE)/g frozen berries. Trolox (6-hydroxy-2,5,7,8-tetramethylchroman-2-carboxylic acid) was used to create a standard curve. The FRAP values were expressed as $\mu \mathrm{mol}$ Trolox equivalent/g frozen berries.

\subsection{Oxygen Radical Absorption Capacity (ORAC)}

This assay has been adapted in US as a standard method for measuring the antioxidant activity in food. The assay measures the decay of fluorescent probe by free radicals which affect the fluorescent intensity in the tested mixture [18]. The damage to the probe is delayed in the presence of antioxidant compounds.

The ORAC assay was conducted as described by Ou et al. [18] with minor modifications. $75 \mathrm{mmol} / \mathrm{L}$ phosphate buffer (PPB) $\mathrm{pH} 7$ was prepared and then stock fluorescein $(2.3 \mu \mathrm{g} / \mathrm{mL}, \mathrm{FL})$ was prepared in PPB. The FL working solution was prepared by mixing 1 part of the stock solution with 49 parts of PPB. The blueberry samples $(25 \mu \mathrm{L})$ were mixed with the working FL solution $(150 \mu \mathrm{L})$ in 96 -well plates. Each plate was incubated at $37^{\circ} \mathrm{C}$ for $15 \mathrm{~min}$ and then freshly prepared AAPH (2,2' azobis(2-methylpropionamidine) dihydrochloride $(25 \mu \mathrm{L})$ was added to the mixture to initiate the reaction. After AAPH addition, the plate was 
immediately placed into the plate reader. Fluorescence was recorded every minute for 90 minutes, using $485 \mathrm{~nm}$ for excitation and $535 \mathrm{~nm}$ for emission.

Trolox was used to create a standard curve. The ORAC values were expressed as $\mu$ mol Trolox equivalent/g frozen berries.

\subsection{Statistical analysis}

Absorbance readings of blueberry samples and standards were corrected for the blank and dilution factor before TPC, FRAP and ORAC values were determined. All measurements were carried out in triplicate across three independent experiments, and results statistically analyzed using SAS Version 9.2 (SAS Institute Inc., Cary, NC, USA). Pearson correlation coefficients $(R)$ between assays were performed using the PROC CORR procedure to achieve the correlation between the phenolic contents and antioxidant activity assays. Oneway analysis of variance (ANOVA) was used to test for significance between means. A difference was considered to be statistically significant when $p<0.05$.

\section{Results}

\subsection{Effect of genotype, solvents and freeze-drying on total phenolic content of blueberries}

Phytochemical concentrations of different rabbiteye blueberry genotypes were found to be varied. When extracted by water alone, 'Tifblue' gave the highest TPC (2.95 mg GAE/ g frozen weight) while 'Rahi' showed the lowest TPC (1.34 mg GAE/ $\mathrm{g}$ frozen weight). In order to see whether acidification enhances extraction efficiency of the solvent, $5 \%$ formic acid-water (v/v) was used as an extracting solvent in comparison with water. The TPC values of the crude extracts prepared in water alone were significantly lower $(P<0.05)$ than those of extracts prepared in 5\% (v/v) formic acid in water (ranged from 2.17 to $3.65 \mathrm{mg} \mathrm{GAE} / \mathrm{g}$ frozen weight). Again, 'Tifblue' showed the highest TPC when extracted by $5 \%$ formic acid-water.

In order to evaluate the effect of freeze-drying on biological properties of blueberries, the whole berries were crushed, frozen at $-20^{\circ} \mathrm{C}$ for 24 hours and then freeze-dried. The powdered freeze-dried whole berries were extracted in water alone. TPC of freeze-dried berries extracted by water ranged from 2.68 to $4.74 \mathrm{mg} \mathrm{GAE} / \mathrm{g}$ frozen weight which were significantly higher than TPC values of the frozen berry water extracts.

Table 1. Total phenolic concentrations (TPC) of frozen berries and freeze-dried berries extracted by water alone or water plus $5 \%$ formic acid. The data are the mean of 3 determinations of 3 independent experiments $(9$ replicates) \pm standard error. The TPC data are expressed as gallic acid equivalent (GAE)/g frozen berries.

\begin{tabular}{|c|c|c|c|c|}
\hline \multirow[b]{2}{*}{ Genotypes } & \multicolumn{2}{|c|}{ Frozen berries extracted with } & \multicolumn{2}{|c|}{ Freeze-dried frozen berries extracted with } \\
\hline & water & $5 \%$ formic acid & water & $5 \%$ formic acid \\
\hline Centurion & $1.79 \pm 0.03^{\mathrm{cB}^{*}}$ & $2.46 \pm 0.01^{b A^{*}}$ & $3.36 \pm 0.01^{b}$ & $9.44 \pm 0.09^{\mathrm{cA}}$ \\
\hline Maru & $2.09 \pm 0.01^{\mathrm{bB}}$ & $2.17 \pm 0.01^{\mathrm{cA}}$ & $2.68 \pm 0.08^{c}$ & $7.42 \pm 0.03^{\mathrm{eA}}$ \\
\hline Rahi & $1.34 \pm 0.01^{\mathrm{eB}}$ & $2.60 \pm 0.01^{\mathrm{bA}}$ & $3.35 \pm \mathbf{0 . 0 3}^{\mathrm{b}}$ & $8.50 \pm 0.003^{\mathrm{dA}}$ \\
\hline Ono & $1.71 \pm 0.07^{\mathrm{dB}}$ & $2.56 \pm 0.01^{\mathrm{bA}}$ & $3.67 \pm 0.08^{b}$ & $9.88 \pm 0.12^{\mathrm{bA}}$ \\
\hline Tifblue & $2.95 \pm 0.004^{\mathrm{aB}}$ & $3.65 \pm 0.03^{\mathrm{aA}}$ & $4.74 \pm 0.01^{\mathrm{a}}$ & $11.56 \pm 0.12^{\mathrm{aA}}$ \\
\hline
\end{tabular}

* Values sharing the same small letters in the same column are not significantly $(P>0.05)$ different among genotypes. Values sharing the same capital letters in the same row are not significantly $(P>0.05)$ different between distilled water and acidified distilled water.

\subsection{Effect of genotype, solvents and freeze-drying on total flavonoid content of blueberries}

Tifblue showed the highest TFC among the five genotypes while 'Maru' and 'Rahi' gave the lowest TFC. TFC was also affected by acidification of solvent and freeze-drying. The TFC of frozen berries extracted by water alone ranged from 0.07 to $0.29 \mathrm{mg} \mathrm{CE} / \mathrm{g}$ frozen weight while the TFC ranged from 0.20 to $0.35 \mathrm{mg}$ $\mathrm{CE} / \mathrm{g}$ frozen weight when the frozen berries were extracted by $5 \%$ formic acid-water. Freeze-dried whole berries extracted by water alone showed significantly higher TFC than their unfreeze-dried counterparts but 'Tifblue' still had the highest TFC.

Table 2. Total flavonoid contents (TFC) of frozen berries and freeze-dried berries extracted by water alone and water plus $5 \%$ formic acid. The data are the mean of 3 determinations of 3 independent experiments ( 9 replicates) \pm standard error. The TFC are expressed in $\mathrm{mg}$ catechin equivalent (CE)/g frozen weight.

\begin{tabular}{|c|c|c|c|c|}
\hline \multirow[b]{2}{*}{ Genotypes } & \multicolumn{2}{|c|}{ Frozen berries extracted with } & \multicolumn{2}{|c|}{ Freeze-dried frozen berries extracted with } \\
\hline & water & $5 \%$ formic acid & water & $\mathbf{5 \%}$ formic acid \\
\hline Centurion & $0.15 \pm 0.007^{b B^{*}}$ & $0.27 \pm 0.004^{\mathrm{bA}}$ & $1.92 \pm 0.01^{b}$ & $3.43 \pm 0.04^{\mathrm{bB}}$ \\
\hline Maru & $0.07 \pm 0.01^{\mathrm{cB}}$ & $0.23 \pm 0.003^{\mathrm{cA}}$ & $1.60 \pm 0.01^{c}$ & $3.16 \pm 0.06^{\mathrm{bcB}}$ \\
\hline Rahi & $0.08 \pm 0.005^{\mathrm{cB}}$ & $0.24 \pm 0.002^{\mathrm{cA}}$ & $1.47 \pm 0.11^{\mathrm{c}}$ & $2.41 \pm 0.04^{\mathrm{cB}}$ \\
\hline
\end{tabular}


Effect of freeze-drying and extraction solvents on the total phenolic contents, total flavonoids

\begin{tabular}{|c|c|c|c|c|}
\hline Ono & $0.17 \pm 0.004^{\mathrm{bB}}$ & $0.20 \pm 0.003^{\mathrm{dA}}$ & $1.41 \pm 0.14^{\mathrm{c}}$ & $3.11 \pm 0.02^{\mathrm{bcB}}$ \\
\hline Tifblue & $0.29 \pm 0.01^{\mathrm{aB}}$ & $0.35 \pm 0.004^{\mathrm{aA}}$ & $2.98 \pm 0.04^{\mathrm{a}}$ & $4.51 \pm 0.04^{\mathrm{aB}}$ \\
\hline
\end{tabular}

* Values sharing the same small letters in the same column are not significantly $(P>0.05)$ different among genotypes. Values denoted with the same capital letters in the same row are not significantly $(P>0.05)$ different between distilled water and acidified distilled water extracts.

\subsection{Effect of genotype, solvents and freeze-drying on antioxidant activity as measured by the ferric reducing antioxidant power (FRAP) assay}

The FRAP values of the extracts prepared from the five genotypes ranged from 9.21 to $14.97 \mu \mathrm{mol}$ Trolox equivalent (TE)/g frozen berries) with 'Tifblue' demonstrating the highest antioxidant activity while 'Rahi' demonstrated the lowest activity. Acidification and freeze-drying also had an effect on antioxidant activity as measured by FRAP assay. The FRAP values of water plus 5\% formic acid extracts ranged from 11.58 to $15.41 \mu \mathrm{mol} \mathrm{TE} / \mathrm{g}$ frozen berries in frozen berries which were significantly higher $(P<0.0001)$ than their water extract counterparts. The freeze-dried whole berries revealed significantly $(P<0.0001)$ higher FRAP values than their unfreeze-dried counterparts. The FRAP values of freeze-dried berry extracts ranged from 21.18 to $44.20 \mu \mathrm{mol} \mathrm{TE} / \mathrm{g}$ frozen berries in frozen berries.

Table 3. Antioxidant activities of five Rabbiteye blueberry genotypes as measured by ferric reducing antioxidant power (FRAP) assay in crude extracts of frozen and freeze-dried berries. These extracts were prepared in water or in water plus 5\% formic acid. The data are expressed as $\mu \mathrm{mol}$ Trolox equivalent (TE) $/ \mathrm{g}$ frozen berries.

\begin{tabular}{|c|c|c|c|c|}
\hline \multirow{2}{*}{ Genotypes } & \multicolumn{2}{|c|}{ Frozen berries extracted with } & \multicolumn{2}{|c|}{ Freeze-dried frozen berries extracted with } \\
\hline & water & $5 \%$ formic acid & water & $5 \%$ formic acid \\
\hline Centurion & $9.93 \pm 0.04^{\mathrm{cB}^{*}}$ & $14.12 \pm 0.05^{\mathrm{cA}^{*}}$ & $24.65 \pm 0.03^{c}$ & $39.38 \pm 0.04^{\mathrm{eA}}$ \\
\hline Maru & $10.08 \pm 0.04^{\mathrm{cB}}$ & $11.58 \pm 0.18^{\mathrm{eA}}$ & $21.18 \pm 0.03^{d}$ & $55.39 \pm 0.07^{\mathrm{cA}}$ \\
\hline Rahi & $9.21 \pm 0.07^{\mathrm{dB}}$ & $14.80 \pm 0.16^{\mathrm{bA}}$ & $24.69 \pm 0.11^{c}$ & $50.48 \pm 0.03^{\mathrm{dA}}$ \\
\hline Ono & $11.54 \pm 0.17^{\mathrm{bB}}$ & $11.87 \pm 0.04^{\mathrm{dA}}$ & $26.40 \pm 0.03^{b}$ & $65.29 \pm 0.07^{\mathrm{bA}}$ \\
\hline Tifblue & $14.97 \pm 0.10^{\mathrm{aB}}$ & $15.41 \pm 0.03^{\mathrm{aA}}$ & $44.20 \pm 0.04^{a}$ & $79.34 \pm 0.72^{\mathrm{aA}}$ \\
\hline
\end{tabular}

* Values denoted with the same small letters in the same column are not significantly $(P>0.05)$ different among genotype. Values denoted with the same capital letters in the same row are not significantly $(P>0.05)$ different between distilled water and acidified distilled water.

\subsection{Effect of genotype, solvents and freeze-drying on antioxidant activity measured by oxygen radical absorbance capacity (ORAC) assay}

ORAC values were also affected by genotypes, acidification and freeze-drying. 'Tifblue' demonstrated the highest ORAC value when extracted by water alone while the ORAC values of other genotypes were not significantly different. When $5 \%$ formic acid-water was used as an extracting solvent, 'Tifblue' and 'Rahi' gave the highest ORAC values at 20.59 and $20.17 \mu \mathrm{mol} \mathrm{TE} / \mathrm{g}$ frozen berries in frozen berries, respectively.

In comparison between frozen and freeze-dried berries, it was found that powdered freeze-dried whole berries showed significantly higher ORAC values than their unfreeze-dried counterparts $(P<0.0001)$. ORAC value of 'Tifblue' freeze-dried water extract was $68.45 \mu \mathrm{mol} \mathrm{TE} / \mathrm{g}$ frozen berries in frozen berries which were the highest among 5 genotypes while 'Maru' gave the lowest ORAC value at $24.53 \mu \mathrm{mol} \mathrm{TE} / \mathrm{g}$ frozen berries in frozen berries.

Table 4. Antioxidant activities of five Rabbiteye blueberry genotypes as measured by oxygen radical absorbance capacity (ORAC) assay in crude extracts of frozen and freeze-dried berries. These extracts were prepared in water and $5 \%$ formic acid-water. The data are expressed as $\mu \mathrm{mol}$ Trolox equivalent (TE)/g frozen berries.

\begin{tabular}{|c|c|c|c|c|}
\hline \multirow[b]{2}{*}{ Genotypes } & \multicolumn{2}{|c|}{ Frozen berries extracted with } & \multicolumn{2}{|c|}{ Freeze-dried frozen berries extracted with } \\
\hline & water & $5 \%$ formic acid & water & $5 \%$ formic acid \\
\hline Centurion & $9.96 \pm 0.79^{\mathrm{cB}^{*}}$ & $18.39 \pm 0.13^{\mathrm{bA}}$ & $39.54 \pm 5.51^{\mathrm{c}}$ & $152.16 \pm 6.35^{\mathrm{cA}}$ \\
\hline Maru & $11.22 \pm 0.43^{\mathrm{bcB}}$ & $16.39 \pm 1.00^{\mathrm{cA}}$ & $24.53 \pm 0.38^{d}$ & $244.29 \pm 19.64^{\mathrm{aA}}$ \\
\hline Rahi & $9.11 \pm 0.08^{\mathrm{cB}}$ & $20.17 \pm 0.03^{\mathrm{aA}}$ & $34.29 \pm 1.12^{c}$ & $196.85 \pm 1.23^{\mathrm{bA}}$ \\
\hline Ono & $11.36 \pm 0.33^{\mathrm{bcB}}$ & $15.50 \pm 0.15^{\mathrm{cA}}$ & $50.48 \pm 2.94^{b}$ & $209.50 \pm 4.59^{\mathrm{bA}}$ \\
\hline Tifblue & $14.27 \pm 0.39^{\mathrm{aB}}$ & $20.59 \pm 0.64^{\text {aA }}$ & $68.45 \pm 2.04^{a}$ & $212.57 \pm 10.17^{\mathrm{abA}}$ \\
\hline
\end{tabular}

* Values denoted with the same small letters in the same column are not significantly $(P>0.05)$ different among genotype. Values denoted with the same capital letters in the same row are not significantly $(P>0.05)$ different between distilled water and acidified distilled water. 


\subsection{Correlation between phytochemicals and antioxidant activities}

Table 5 shows that FRAP values are positively correlated with TPC $\left(R^{2}=0.9017\right)$ and with TFC $\left(R^{2}=\right.$ $0.9319)$. The ORAC values also showed positive correlation with TPC and TFC with $R^{2}$ values of 0.8819 and 0.8706 , respectively (Table 5).

Table 5. Correlation (correlation coefficient, $R^{2}$ values) between the antioxidant compounds [total phenolic contents (TPC) and total flavonoid contents (TFC)] versus antioxidant activity as measured by the ferric reducing antioxidant power (FRAP) and oxygen radical absorbance capacity (ORAC)].

\begin{tabular}{c|cccc} 
& \multicolumn{3}{c}{ Antioxidants } \\
Phytochemicals & All extracts & \multicolumn{1}{c}{ FRAP } & All extracts & ORAC \\
TPC & 0.8897 & 0.5068 & 0.8788 & $5 \%$ FAE \\
\hline TFC & 0.8912 & 0.6021 & 0.7535 & 0.4450 \\
\hline
\end{tabular}

*FAE: Formic acid extract

\section{Discussion}

The results of this study showed that total phenolic concentrations (TPC) and total flavonoid concentrations (TFC) of the tested blueberry genotypes varied significantly and 'Tifblue' always demonstrated the highest values while 'Maru' was often amongst the lowest values. The TPC values reported by Prior et al. [19], Moyer et al. [20], Sellappan et al. [21], Howard et al. [22], and You et al. [23] ranged from 0.44 to $9.52 \mathrm{mg}$ $\mathrm{GAE} / \mathrm{g}$ frozen berries. The TPC values in this study are comparable with the results reported previously for blueberry genotypes grown in different countries. The variations in TPC observed between different studies and between different genotypes may be related to the differences in genetic and environmental conditions. Howard et al. [22] reported that the TPC of some blueberry genotypes varied between growing seasons, suggesting that environmental growing conditions can affect levels of phenolic compounds in blueberries.

Total flavonoid contents of blueberries grown in Bulgaria have been reported by Marinova et al. [24] to be $1.9 \mathrm{mg}$ catechin equivalent $(\mathrm{CE}) / \mathrm{g}$ fruit weight. In the present study, the total flavonoid content ranged between 1.41 and $2.98 \mathrm{mg} \mathrm{CE} / \mathrm{mg}$ frozen berries when the berries were freeze-dried.

The present study showed that acidification of the extracting distilled water by $5 \%$ formic acid has led to a significant increase in the TPC, TFC and antioxidant activity as measured by FRAP and ORAC assays. Various organic acids have been used to enhance extraction efficiency of solvents. Kalt et al. [13] found that acidification of extracting solvent by hydrochloric acid was not only enhancing extraction but also stabilized anthocyanin in the extracts and increased their antioxidant activity as measured by ORAC method. Recently, Michiels et al. [25] showed that a small concentration of acetic acid in an extraction solvent had an influence on the total phenolic content and antioxidant activity of the plant extracts. Organic acids such as formic acid are more aggressive solvents than water alone and lead to higher extractability of phytochemicals. Even though formic acid may cause anthocyanin acylation [26], it has been used widely in the preparation of plant extracts for polyphenol determination in HPLC. Moreover, addition of formic acid in HPLC mobile phase also helps in enhancing separation of phenolic acids and improving chromatographic resolution [21].

In all cultivars, freeze-drying the whole berries prepared in water alone has led to a significant increase $(P<0.05)$ in TPC, TFC and antioxidant activity as measured by FRAP and ORAC assays. Even though freezedrying process is more costly and time consuming than the conventional drying method, it is widely used since it can preserve the nutritional aspects of the food products. Recently, Shofian et al. [8] reported that TPC values of some tropical fruits were significantly different between fresh and freeze-dried fruits. In contrast, Reyes et al. [27] have found that even though the ascorbic acid in blueberries decreased after freeze-drying, phytochemical content and antioxidant activity of the freeze-dried blueberries were slightly increased.

Although, it is difficult to compare between blueberry and wheat grass, Das et al. [14] have found that total flavonoid contents of wheat grass were higher after freeze-drying process. This might be due to the release of the compounds from the ruptured plant cells during freeze-drying process. In addition, Perez-Gregorio et al. [28] reported that onions subjected to freezing showed reduced level of flavonols whereas freeze-dried samples showed higher amount of flavonols. The authors attributed this increment to the possibility of liberation of phenolic compounds from onion during freeze-drying.

Various studies showed that freeze-drying affects antioxidant activity. Shofian et al. [8] found that the FRAP values of freeze-dried fruits were significantly lower than the fresh fruits while, in some other fruits the FRAP values of freeze-dried form remained unchanged. Reyes et al. [28] reported that antioxidant activity of the extracts from freeze-dried blueberry was not significantly different from the fresh berries.

In our study, ORAC values ranged from 9.11 to $68.45 \mu \mathrm{mol} \mathrm{TE} / \mathrm{g}$ frozen berries which were comparable to ORAC values from other studies. The ORAC values of rabbiteye genotypes ranged from 33.8 to 
$130.7 \mu \mathrm{mol} \mathrm{TE} / \mathrm{g}$ frozen berries [20, 23, 29]. In highbush genotypes, the ORAC values ranged from 20.5 to 73.1 $\mu \mathrm{mol} \mathrm{TE} / \mathrm{g}$ frozen berries [22].

In all assays, 'Tifblue' demonstrated the highest TPC, TFC and antioxidant activities. Sellappan et al. [21] reported that 'Tifblue' had the highest concentration of gallic acid $(2.59 \mathrm{mg} / \mathrm{g})$ and ferulic acid $(1.7 \mathrm{mg} / \mathrm{g})$ among the Rabbiteye blueberry genotypes.

Based on the strong correlation between phenolic compounds and antioxidant activities, as measured by FRAP and ORAC, it can be concluded that antioxidant capacity of blueberries is likely to relate to phenolic compounds. Shofian et al. [8] reported that TPC values of tropical fruits were significantly correlated with their FRAP values. This may indicate that phenolic compounds of blueberry extracts were responsible for antioxidant activities. A significant correlation between ORAC values and TPC values in berry fruits was also reported previously $[19,29]$.

\section{Conclusion}

We can conclude that among the tested blueberry genotypes, 'Tifblue' was found to be the most powerful source of phytochemicals that showed strong antioxidant capacities. The present study showed that acidification of distilled water by $5 \%$ of formic acid significantly increased its efficiency as an extraction solvent. Freeze-drying proved to be a suitable method for blueberry processing because the phytochemicals and antioxidant activity were either increased or at least unchanged. Based on the correlation between phenolic compounds and antioxidant activities, as measured by FRAP and ORAC, it can be concluded that antioxidant capacity of blueberries may relate to phenolic compounds and different phenolic compounds may exhibit different level of antioxidant.

\section{References}

[1] Lila, M. A. (2004). Anthocyanins and human health: an in vitro investigation approach. Journal of Biomedicine and Biotechnology, 5, 306-313.

[2] Stevenson D. E. and Hurst R. D. (2007). Polyphenolic phytochemicals - just antioxidants or much more? Cell and Molecular Life Science 64, 2900-16.

[3] Seeram, N. P. (2008). Berry fruits for cancer prevention: Current status and future prospects. Journal of Agricultural and Food Chemistry, 56, 630-635.

[4] Kay, C. D. and Holub, B. J. (2002). The effect of wild blueberry (Vaccinicum angustifolium) consumption on postprandial serum antioxidant status in human subjects. British Journal of Nutrition, 88, 389-398.

[5] Lohachoompol, V., Srzednicki, G., and Craske, J. (2004). The change of total anthocyanins in blueberries and their antioxidant effect after drying and freezing. Journal of Biomedicine and Biotechnology, 5, 248-252.

[6] Svarcova, I., Heinrich, J., and Valentova, K. (2007). Berry fruits as a source of biologically active compounds: The case of Lonicera Caerulea._Biomedical papers of the Medical Faculty of the University Palacký, Olomouc, Czech Republic. 151, $163-174$.

[7] Samappito, S., and Butkup, L. (2010). Analysis of anthocyanin, flavonoids, and phenolic acid contents of ten fruits and antioxidant activity. International of Journal of Fruit Science, 10, 264-280.

[8] Shofian, M. N., Hamid, A. A., Osman, A., Saari, N., Anwar, F., Dek, M. S. P., and Hairuddin, M. R. (2011). Effect of freeze-drying on the antioxidant compounds and antioxidant activity of selected tropical fruits. International Journal of Molecular Sciences, 12 , 4678-4692.

[9] Birt, D. F., Hendrich, S., and Wang, W. Q. (2001). Dietary agents in cancer prevention: Flavonoids and isoflavonoids. Pharmacology and Therapeutics, 90, 157-177.

[10] Smith, M. A. L., Marley, K. A., Seigler, D., Singletary, K. W., and Meline, B. (2000). Bioactive properties of wild blu eberry fruits. Journal of Food Science, 65, 352-356.

[11] Kylli, P. (2011). Berry phenolics: isolation, analysis, identification, and antioxidant properties. Academic dissertation. University of Helsinki. Helsinki, Finland.

[12] Tuberoso, C. I. G., Rosa, A., Bifulco, E., Melis, M. P., Atzeri, A., Pirisi, F. M., and Dessì, M. A. (2010). Chemical composition and antioxidant activities of Myrtus communis L. berries extracts. Food Chemistry, 123, 1242-1251.

[13] Kalt, W., McDonald, J. E., and Donner, H. (2000). Anthocyanins, phenolics and antioxidant capacity of processed lowbush blueberry products. Journal of Food Science, 65(3), 390-393.

[14] Das, A., Raychaudhuri, U., and Chakraborty, R. (2012). Effect of freeze drying and oven drying on antioxidant properties of fresh wheatgrass. International Journal of Food Sciences and Nutrition, 63, 718-721.

[15] Kumar, S., Kumar, D., and Prakash, O. (2008). Evaluation of antioxidant potential, phenolic and flavonoid contents of Hibiscus Tiliaceus flowers. Electronic Journal of Environmental, Agriculture and Food Chemistry, 7(4), 2863-2871.

[16] Benzie, I. F. F., and Strain, J. J. (1996). The ferric reducing ability of plasma (FRAP) as a measure of 'antioxidant power': the FRAP assay. Analytical Biochemistry, 239, 70-76.

[17] Molan, A. L., Flanagan, J., Wei, W., and Moughan P. J. (2009) Selenium containing green tea has higher antioxidant and prebiotic activities than regular green tea. Food Chemistry, 114, 829-835.

[18] Ou, B. X., Hampsch-Woodill, M., and Prior, R. L. (2001) Development and validation of an improved oxygen radical absorbance capacity assay using fluorescein as the fluorescent probe. Journal of Agricultural and Food Chemistry, 49, 4619-4626.

[19] Prior, R. L., Cao, G., Martin, A., Sofic, E., McEwen, J., O’Brien, C., Liscner, N., Ehlenfeldt, M., Kalt, W., Krewer, G. and Mainland, C. M. (1998). Antioxidant capacity as influenced by total phenolic and anthocyanin content, maturity and variety of Vaccinicum species. Journal of Agricultural and Food Chemistry, 46, 2686-2693.

[20] Moyer, R. A., Hummer, K. E., Finn, C. E., Frei, B., and Wrolstad, R. E. (2002). Anthocyanin, phenolics and antioxidant capacity in diverse small fruits: Vaccinicum, Rubus and Ribes. Journal of Agricultural and Food Chemistry, 50, 519-525.

[21] Sellappan, S. Akoh, C. C., and Krewer, G. (2002). Phenolic compounds and antioxidant capacity of georgia-grown blueberries and blackberries. Journal of Agricultural and Food Chemistry, 50 (8), 2432-2438. 
[22] Howard, L. R., Clark, J. R., and Brownmiller, C. (2003). Antioxidant capacity and phenolic content in blueberries as affected by genotype and growing season. Journal of the Science of Food and Agriculture, 83, 1238-1247.

[23] You, Q., Wang, B., Chen, F., Huang, Z., Wang, X., and Luo, P. G. (2011). Comaprison of anthocyanins and phenolics in organically and conventionally grown blueberries in selected cultivars . Food Chemistry, 125, 201-208.

[24] Marinova, D., Ribarova, F., and Atnanassova, M. (2005). Total phenolics and total flavonoids in Bulgarian fruits and vegetables. Journal of University of Chemical Technology and Metallurgy, 40(3), 255-260.

[25] Michiels, J. A., Kevers, C., Pincemail, J., Defraigne, J. O., and Dommes, J. (2012). Extraction conditions can greatly influence antioxidant capacity assays in plant food matrices. Food Chemistry, 130, 986-993.

[26] Escribano-Bailón, M. T., and Santos-Buelga, C. (2003). Polyphenol extraction from foods. In G. Williamson and C. Santos-Buelga (Eds.), Methods in Polyphenol Analysis (pp 1-16). London, U.K: Royal Society of Chemistry.

[27] Reyes, A., Evseev, A., Mahn, A., Bubnovich, V., Bustos, R., and Scheuermann, E. (2011). Effect of operating conditions in freezedrying on the nutritional properties of blueberries. International Journal of Food Sciences and Nutrition, 62, $303-306$.

[28] Pérez-Gregorio M. R., and Garcia-Falcon M.S. (2011). Flavonoids changes in fresh-cut onions during storage in different packaging systems. Food Chemistry, 124,652-658.

[29] Wang, S. Y., Chen, H., and Ehlenfeldt, M. K. (2011). Antioxidant capacities vary substantially among cultivars of rabbiteye blueberry (Vaccinicum ashei Reade). International Journal of Food Science and Technology, 46, 2482-2490. 